\title{
Revisiting the Key Optical and Electrical Characteristics in Reporting Photocatalysis of Semiconductors
}

\author{
Dai-Phat Bui*, Minh-Thuan Pham, Hong-Huy Tran, Thanh-Dat Nguyen, Thi Minh Cao, \\ Viet Van Pham* \\ Photocatalysis Research Group (PRG), Faculty of Materials Science and Technology, \\ University of Science, VNU-HCM, 227 Nguyen Van Cu Street, District 5, Ho Chi Minh \\ City, 700000, Viet Nam
}

Corresponding authors: daiphatbui301196@gmail.com (Dai-Phat Bui) and pvviet@hcmus.edu.vn (Viet Van Pham)

\section{The bigger picture:}

Photocatalysis has been studied and considered as a green and effective approach in addressing environmental pollution. However, factors that affect photocatalytic performance have not been systematically studied. In this work, we have presented a comprehensive roadmap for characterizing, interpreting, and reporting semiconductors' electrical and optical properties through routinely used techniques (XPS, DRS, PL) in the context of photocatalysis. Having deeply and precisely studied the band structure of three representative photocatalysts, we have presented and highlighted essential information and details, which are critical and beneficial for studies of (1) band alignments, (2) redox potentials, and (3) defects. Further works with a comprehensive understanding of band structure are desirable and hold great promise.

\section{Summary}

Semiconductor photocatalysts are being extensively studied for energy and environmental settings because of their high efficiency and sustainability. Despite their great progress, most current photocatalysts are inherently shortcoming to become the cornerstone and convincingly lead the field forward. Previous studies focus on the efficiency of photocatalysts solely that fails to consider the key properties that greatly influence the reported photocatalytic performance. Such properties concern the structure and 
arrangement of photocatalysts bandgap, which establishes the redox ability, the lifespan of the free radicals, activation energy, and the applications. This work highlights key techniques intensively used in studying the band structure, the results processing methods, and the mistakes involved. Overall, this perspective proposes a critical discussion that will be helpful for scientists working on photocatalysts and informative for others.

Keywords: Band structure; Optical property; Electrical property; DRS; Mott-Schottky; Photoluminescence; UPS; XPS.

\section{Introduction}

Global warming has been becoming increasingly serious that triggers extreme concerns across the globe. It comes from environmental pollution, including air, soil, and water pollution ${ }^{1}$. In the scientific domains, environmental pollution alters the environment's chemical, physical and biological nature; it is the reason for an estimated 12.6 million deaths each year ${ }^{2}$. Thus, finding new technologies and methods to address environmental pollution is critical. Various methods are performed to address pollutants, including ion exchange, flotation, media filtration, centrifugation, and adsorption approaches. However, there are limitations due to high operating costs, low efficiency, poor recyclability, and toxic by-products ${ }^{3,4}$.

Photocatalysis has been studied and considered a green and effective approach in addressing environmental pollution ${ }^{4}$. Photocatalysis has attracted for its versatility in the environment and energy sector. In the environmental field, photocatalysts can be used to remove pollutants in the air and water. The photocatalytic process can eliminate the total toxicity with products of $\mathrm{CO}_{2}$, water, and other fewer substances ${ }^{5}$. In the energy field, photocatalysts can generate alternative fuels such as $\mathrm{H}_{2}, \mathrm{O}_{2}$, and bioethanol via splitting $\mathrm{H}_{2} \mathrm{O}$ or reducing $\mathrm{CO}_{2}{ }^{6}$. In the photocatalytic process, photocatalysts are activated by a suitable light source to induce photocatalytic reactions. The use of light gives photocatalytic technology a great advantage compared to other waste treatment methods such as adsorption or filtration. However, the catalysts' optical and electrical properties and photocatalytic mechanisms are not paid needed attention to compared to the sole 
efficiency. ${ }^{7}$ This causes difficulties to understand the mechanism of decomposition of pollutants and future photocatalytic application.

This work highlights key techniques to study optical and electrical properties in reporting photocatalysis. In addition, the current mistakes and inconsistencies in interpreting these properties are presented and revised. Here, $\mathrm{TiO}_{2}, \mathrm{~g}_{-} \mathrm{C}_{3} \mathrm{~N}_{4}$, and $\mathrm{SnO}_{2}$ are used as representatives because $\mathrm{TiO}_{2}$ is the most studied photocatalyst (accounting for $52.5 \%$ of studies in this field, Web of Science, March 2021), $\mathrm{g}-\mathrm{C}_{3} \mathrm{~N}_{4}$ is an emerging nonmetallic photocatalyst (7.8\%), and $\mathrm{SnO} 2$ is an emerging photocatalyst (1.6\%). The bandgap of $\mathrm{TiO}_{2}, \mathrm{SnO}_{2}, \mathrm{~g}_{-} \mathrm{C}_{3} \mathrm{~N}_{4}$ is determined by diffuse reflectance spectroscopy (DRS), choosing the compatible light source becomes more straightforward. The conduction band (CB) positions and the valence band (VB), which determine the redox abilities, are obtained by the Mott-Schottky technique. The supporting states in the bandgap of the materials are investigated by Photoluminescence (PL). The band structure of their composites is studied by X-ray Photoelectron Spectroscopy (XPS) and Ultraviolet Photoelectron Spectroscopy (UPS). The understanding of optical and electrical features of photocatalysts not only supports research expansion into new materials/composites and but also enables researchers to design wastewater or air pollution treatment systems with the suitable operation time, area, light source, and conditions, which helps to optimize the photocatalytic activity of photocatalysts and systems.

\section{Diffuse Reflectance Spectroscopy Analysis}

It is essential to know the bandgap energy to determine the right light source for activating photocatalysis. The photon energy should be higher than the bandgap energy of the photocatalyst to generate electron-hole pairs. The DRS is often used to determine the bandgap energy of photocatalysts. DRS results are plotted with reflectance or absorbance as the vertical axis vs. wavelength as the horizontal axis. To determine bandgap, the eqn. (1) is used to transform wavelength into energy as a new horizontal axis. The Tauc equation (eqn. (2)) and Kubelka Munk equation (eqn. (3)) transform the absorbance and the reflectance into a new vertical axis, respectively ${ }^{8-10}$. The parameters of these equations are calculated as eqn. (4) - eqn. (8). The bandgap energy is determined by the tangent of the 
plot with Ox. It is useful for single-component photocatalysts and heterojunctions ${ }^{11-13}$. However, the absorbance should not be converted into reflectance or vice versa by eqn. (9) or eqn. (10) due to the significant change of bandgap energy. Also, photocatalysts with similar bandgap energies could behave differently. This shows that the photocatalytic behaviors depend not only on the bandgap value but also on the positions of the conduction band and valence band of materials, which DRS cannot determine. The next sections will explain these phenomena and discuss the band structure of photocatalysts.

$$
\begin{gathered}
\mathrm{E}=\mathrm{h} v=\frac{\mathrm{hc}}{\lambda} \\
(\alpha \mathrm{h} v)^{\mathrm{r}}=\mathrm{B}\left(\mathrm{h} v-\mathrm{E}_{\mathrm{g}}\right) \\
(\mathrm{F}(\mathrm{R}) \mathrm{h} v)^{\mathrm{r}}=\mathrm{B}\left(\mathrm{h} v-\mathrm{E}_{\mathrm{g}}\right) \\
\alpha=\mathrm{A} \frac{\ln (10)}{1} \\
\left(\mathrm{~A} \frac{\ln (10)}{1} \mathrm{~h} v\right)^{\mathrm{r}}=\mathrm{B}\left(\mathrm{h} v-\mathrm{E}_{\mathrm{g}}\right) \\
\alpha=\mathrm{F}(\mathrm{R}) \\
\mathrm{F}(\mathrm{R})=\frac{\mathrm{K}}{\mathrm{S}} \\
\mathrm{F}(\mathrm{R})=\frac{\left(1-\mathrm{R}_{\mathrm{d}}\right)^{2}}{2 \mathrm{R}_{\mathrm{d}}} \\
\mathrm{A}=\log \left(\frac{1}{\mathrm{R}}\right) \\
\left(\log \left(\frac{1}{\mathrm{R}}\right) \frac{\ln (10)}{1} \mathrm{~h} v\right)^{\mathrm{r}}=\mathrm{B}\left(\mathrm{h} v-\mathrm{E}_{\mathrm{g}}\right)
\end{gathered}
$$

where E is Photon energy (eV), h is Planck's constant $\left(4.132 \times 10^{-15} \mathrm{eV} . \mathrm{s}\right), \mathrm{v}$ is the frequency $\left(\mathrm{s}^{-1}\right), \mathrm{c}$ is photon velocity $(\mathrm{nm}), \lambda$ is the wavelength $(\mathrm{nm}), \alpha$ is absorption coefficients from absorption mode, $\mathrm{B}$ is constant, and $\mathrm{E}_{\mathrm{g}}$ is bandgap $(\mathrm{eV}), \mathrm{A}$ is absorbance value, 1 is sample width $(\mathrm{cm}), \mathrm{R}$ is reflectance value, $\mathrm{K}$ is absorption coefficient from reflectance mode, and 
$\mathrm{S}$ is scattering coefficient from reflectance mode. For direct and indirect bandgaps, $\mathrm{r}$ is equal to 2 and $1 / 2$, respectively.

Figure 1 (a) shows the absorbance of $\mathrm{TiO}_{2}, \mathrm{SnO}_{2}$, and $\mathrm{g}-\mathrm{C}_{3} \mathrm{~N}_{4}$. Determining the bandgap by absorbance plots is insufficient because it cannot determine whether the bandgap is direct or indirect. Moreover, the determined bandgap inconsistent with theoretical results. So, the Tauc equation (2) should be used to determine the direct bandgaps and indirect bandgaps via the tangent of Tauc plots of $(\alpha h v)^{2}$ vs. energy (Figure $\left.1(b)\right)$ and $(\alpha h v)^{1 / 2}$ vs. energy (Figure 1 (c)). The direct bandgaps are higher than the indirect bandgap for all materials. Figure 1 (d) shows the bandgaps of $\mathrm{TiO}_{2}(3.36 \mathrm{eV}$ for direct bandgap and $2.91 \mathrm{eV}$ for indirect bandgap), $\mathrm{SnO}_{2}(3.45 \mathrm{eV}$ and $2.87 \mathrm{eV})$, and $\mathrm{g}_{-} \mathrm{C}_{3} \mathrm{~N}_{4}(2.71 \mathrm{eV}$ and $2.39 \mathrm{eV})$. Although it is not yet possible to choose between the direct or indirect bandgaps, knowing in advance, the maximum possible bandgap also helps choose the light source. Choosing the right bandgaps and determining the bandgap positions that affect the photocatalysts' redox abilities are discussed in the next section. 

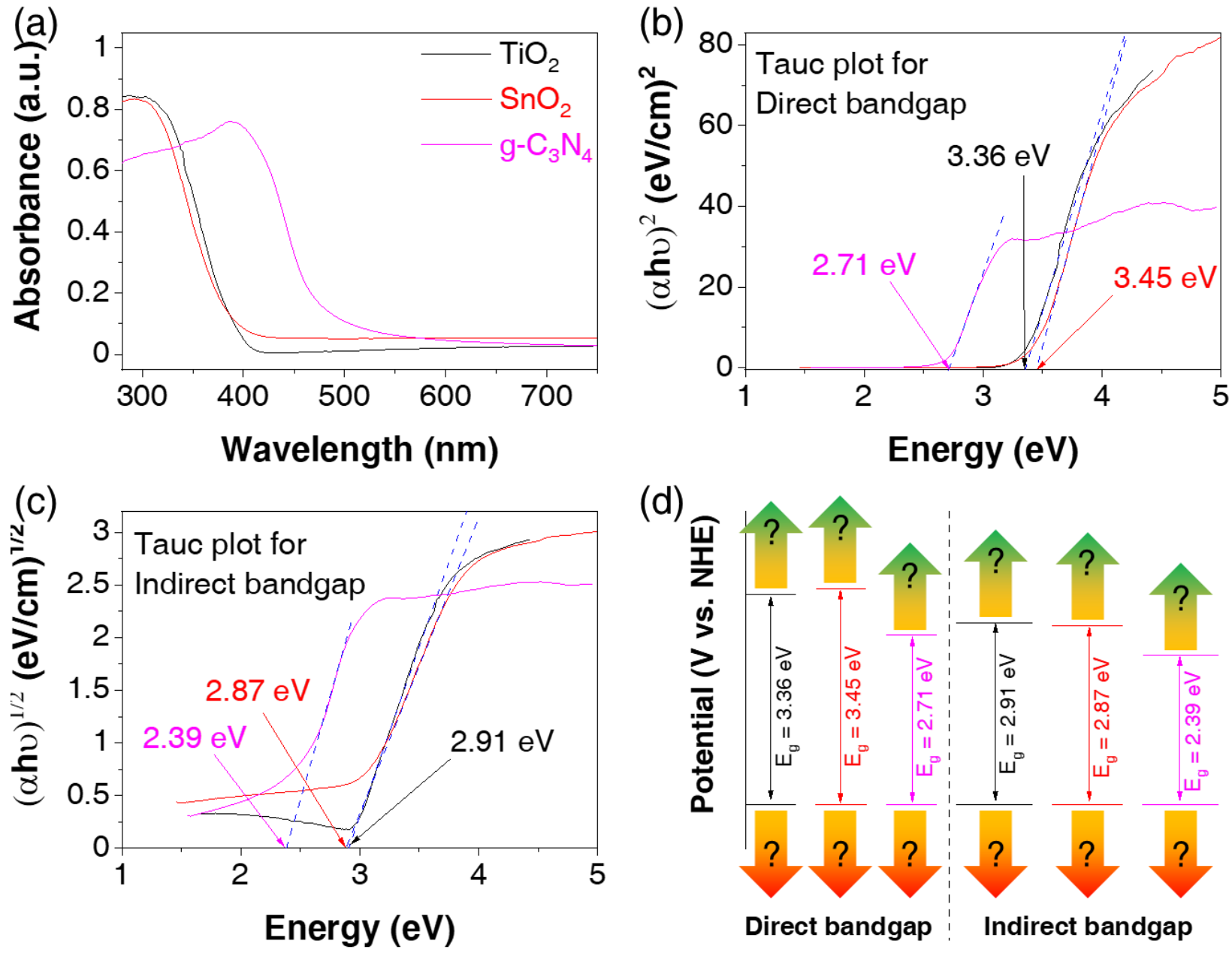

(d)

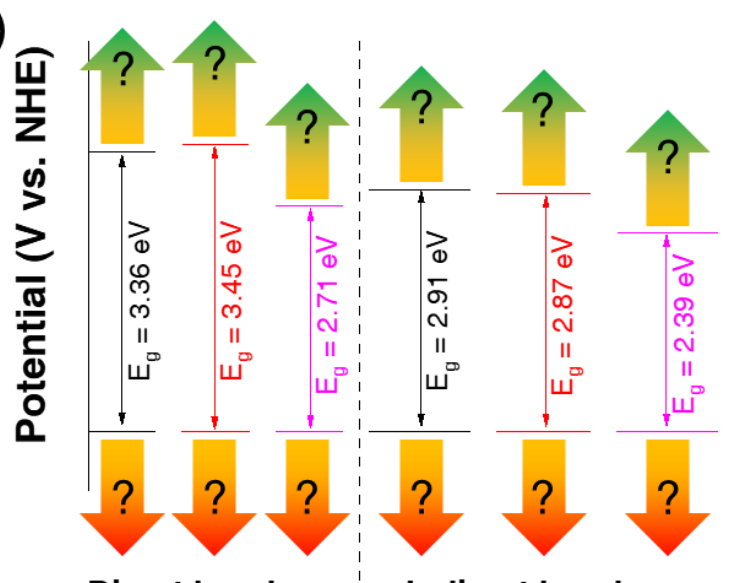

Figure 1. DRS spectra (a), Tauc plots of $(\alpha h v)^{2}$ vs. energy (b) and $(\alpha h v)^{1 / 2} v s$. energy (c) of $\mathrm{TiO}_{2}, \mathrm{SnO}_{2}$, and $\mathrm{g}-\mathrm{C}_{3} \mathrm{~N}_{4}$. Direct and indirect bandgaps of materials (d). DRS spectra cannot determine the positions of the conduction band and valence band of materials ${ }^{14,15}$.

\section{Electrochemical techniques}

Photocatalysts having the same bandgap but behave differently because the position of conduction band minimum (CBM) and valence band maximum (VBM) determines their redox ability. In previous reports, the Mott-Schottky technique is used to determine the CB position. For the Mott-Schottky technique, the apparent capacitance is measured as a function of potential and by eqn. (11) ${ }^{16}$. The CBM can be determined by extrapolation of $\mathrm{C}=0$. The obtained CBM value is versus the reference electrode and conductive media. The most populated reference electrodes are calomel electrode (CE) $\left(\mathrm{Hg}_{2} \mathrm{Cl}_{2} / \mathrm{Hg}, \mathrm{Cl}^{-}\right)$, normal hydrogen electrode $(\mathrm{NHE})\left(\mathrm{H}^{+} / \mathrm{H}_{2}\right)$, and silver - silver chloride electrode 
$(\mathrm{Ag} / \mathrm{AgCl})$. The conductive media is often $\mathrm{KCl}$ with a concentration of $0.1 \mathrm{M}, 1 \mathrm{M}, 3.5 \mathrm{M}$, or saturation. However, the reports should obtain a CBM level vs. NHE via conversing CBM level vs. different electrode and media systems by eqn. (12) to reach consistency in studies. Combing this result with the bandgap energy from DRS, the VBM vs. NHE can be determined. These understandings could help investigate and choose the right applications for photocatalysts because excited electrons must move from the $\mathrm{CB}$ to lower redox potentials and holes must move from VB to higher redox potentials. The redox potentials for various species and their change to $\mathrm{pH}$ via the Nernst equation (eqn. (13)) were thoroughly reviewed by Li et al. in $2016 .{ }^{17}$ For water splitting, photocatalysts with CBM lower than $-0.41 \mathrm{~V}$ vs. $\mathrm{NHE}\left(\mathrm{E}_{2 \mathrm{H}^{+} / \mathrm{H}_{2}}, \mathrm{pH}=7\right)$ are facilitated to reduce $\mathrm{H}_{2} \mathrm{O}$ into $\mathrm{H}_{2}$ while photocatalysts with VBM higher than $0.82 \mathrm{~V}$ vs. $\mathrm{NHE}\left(\mathrm{E}_{\mathrm{O}_{2} / \mathrm{H}_{2} \mathrm{O}}, \mathrm{pH}=7\right)$ are facilitated to oxidize $\mathrm{H}_{2} \mathrm{O}$ into $\mathrm{O}_{2}$. For environmental application, photocatalysts with $\mathrm{CBM}$ lower than $-0.78 \mathrm{~V}$ vs. $\mathrm{NHE}\left(\bullet \mathrm{OH} / \mathrm{OH}^{-}, \mathrm{pH}=7\right)$ and VBM higher than $2.28 \mathrm{~V}$ vs. NHE $\left(\mathrm{E}_{\bullet \mathrm{oH}^{\circ} \mathrm{OH}^{-}}\right.$, $\mathrm{pH}=7$ ) are favored because they can produce $\bullet \mathrm{O}_{2}$ and $\bullet \mathrm{OH}$ radicals to degrade pollutants. In addition, with the simplest approach, the CB and VB of photocatalysts are considered shifting at the same magnitude but in opposite directions in heterojunctions.

$$
\begin{gathered}
\frac{1}{\mathrm{C}_{\mathrm{SC}}^{2}}=\frac{2}{\mathrm{e} \varepsilon \varepsilon_{0} \mathrm{NA}^{2}}\left(\mathrm{E}-\mathrm{E}_{\mathrm{FB}}-\frac{\mathrm{kT}}{\mathrm{e}}\right) \\
\mathrm{E}^{\circ}=\mathrm{E}_{\mathrm{NHE}}^{25^{\circ} \mathrm{C}, \mathrm{pH}=0}=\mathrm{E}+\mathrm{c} \\
\mathrm{E}^{\mathrm{pH}}=\mathrm{E}^{\circ}-0.059 \mathrm{pH}
\end{gathered}
$$

When $\mathrm{C}_{\mathrm{SC}}$ is the space charge capacitance, e is the electron charge $\left(\mathrm{F}_{\mathrm{cm}} \mathrm{cm}^{-2}\right), \varepsilon$ is the dielectric constant of reaction, $\varepsilon_{0}$ is the vacuum permittivity, $\mathrm{N}$ is the number of donors, $\mathrm{k}$ is Boltzmann constant, $\mathrm{T}$ is the experiment temperature $(\mathrm{K})$, and $\mathrm{A}$ is the surface area of electrode contact with the electrolyte $(\mathrm{cm})$. $\mathrm{E}$ is the applied potential $(\mathrm{V})$. The $\mathrm{E}_{\mathrm{FB}}$ is estimated by extrapolating a linear fit of the MS plot to obtain the x-intercept (V). c values are shown in Table 1. $\frac{\mathrm{kT}}{\mathrm{e}}$ is about $0.0257 \mathrm{~V}$ at $25^{\circ} \mathrm{C}$.

Table 1. c values for conversion of the applied potential vs. different electrodes to vs. NHE. 


\begin{tabular}{ccc}
\hline Electrode & c $(\mathbf{V})$ & Reference \\
\hline $\mathrm{Hg} / \mathrm{Hg}_{2} \mathrm{Cl}_{2}, \mathrm{KCl} 0,1 \mathrm{M}$ & 0.334 & 18 \\
$\mathrm{Hg} / \mathrm{Hg}_{2} \mathrm{Cl}_{2}, \mathrm{KCl} 1 \mathrm{M}$ & 0.280 & 18 \\
$\mathrm{Hg} / \mathrm{Hg}_{2} \mathrm{Cl}_{2}, \mathrm{KCl} 3.5 \mathrm{M}$ & 0.250 & 19 \\
$\mathrm{Hg} / \mathrm{Hg}_{2} \mathrm{Cl}_{2}, \mathrm{KCl}$ saturated & 0.241 & 18 \\
$\mathrm{Hg} / \mathrm{Hg}_{2} \mathrm{Cl} 2, \mathrm{NaCl}$ saturated & 0.236 & 20 \\
$\mathrm{Ag} / \mathrm{AgCl}, \mathrm{KCl} 0.1 \mathrm{M}$ & 0.288 & 18 \\
$\mathrm{Ag} / \mathrm{AgCl}, \mathrm{KCl} 3 \mathrm{M}$ & 0.210 & 21 \\
$\mathrm{Ag} / \mathrm{AgCl}, \mathrm{KCl} 3.5 \mathrm{M}$ & 0.205 & 22 \\
$\mathrm{Ag} / \mathrm{AgCl}, \mathrm{KCl}$ saturated & 0.199 & 22 \\
$\mathrm{Ag} / \mathrm{AgCl}, \mathrm{NaCl} 3 \mathrm{M}$ & 0.209 & 18 \\
$\mathrm{Ag} / \mathrm{AgCl}, \mathrm{NaCl}$ saturated & 0.197 & 18 \\
\hline
\end{tabular}

Figure 2 (a) displays the Mott-Schottky plots of $\mathrm{TiO}_{2}, \mathrm{SnO}_{2}$, and $\mathrm{g}-\mathrm{C}_{3} \mathrm{~N}_{4}$. The linear potential parts of Mott-Schottky plots are used to determine the CBM position of $\mathrm{TiO}_{2}$, $\mathrm{SnO}_{2}$, and $\mathrm{g}-\mathrm{C}_{3} \mathrm{~N}_{4}$, which are calculated as $-0.55,0.51$, and $-0.51 \mathrm{eV}$ vs. $\mathrm{Ag} / \mathrm{AgCl}$ electrode, respectively. As shown in Figure 2 (b), the typical values for the CBM position of materials are converted from unit $\mathrm{V}$ vs. $\mathrm{Ag} / \mathrm{AgCl}$ to $\mathrm{V}$ vs. NHE (eqn. (12)) for easy comparison of the future. Combining with DRS results and previous studies on bandgap types of $\mathrm{TiO}_{2}$, $\mathrm{SnO}_{2}$, and $\mathrm{g}_{-} \mathrm{C}_{3} \mathrm{~N}_{4}$, the band alignment is illustrated in Figure 2 (c). When receiving enough excitation energy, the photogenerated electrons move from VB to $\mathrm{CB}$ and reduce absorbed oxygen $\left(\right.$ or $\mathrm{H}^{+}$) on the surface to $\bullet \mathrm{O}_{2}$ radicals $\left(\right.$ or $\mathrm{H}_{2}$ ). Although the $\mathrm{CB}$ and $\mathrm{VB}$ position has a lower potential than the potential of $\mathrm{O}_{2} / \bullet \mathrm{O}_{2}$ and $\bullet \mathrm{OH} / \mathrm{OH}^{-}$, previous reports also recorded reactions caused by these free radicals. It could be due to the states in the bandgap, which are discussed in the next section. 

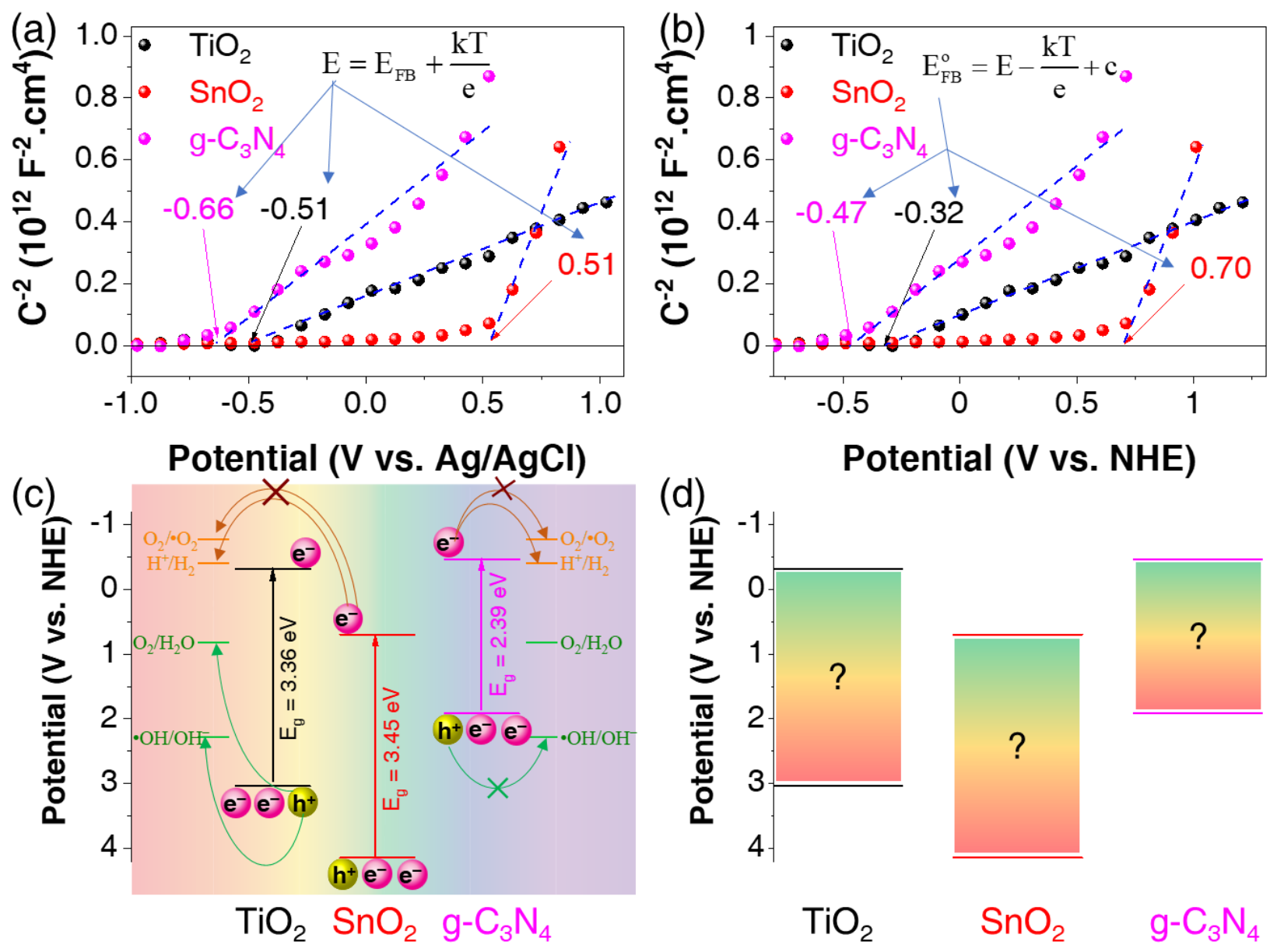

Figure 2. Mott-Schottky plots vs. $\mathrm{Ag} / \mathrm{AgCl}$ reference electrode (a) and vs. normal hydrogen electrode (b) of $\mathrm{TiO}_{2}, \mathrm{SnO}_{2}$, and $\mathrm{g}-\mathrm{C}_{3} \mathrm{~N}_{4}$. Band positions of materials (c). The combination of DRS spectra and Mott-Schottky cannot determine the supporting states in the bandgap of materials ${ }^{23,24}$.

\section{Photoluminescence Spectroscopy}

Defects in the photocatalysts are among the factors contributing to photocatalytic performance, and they prolong the lifetime of electron-hole pairs via adding trapping states in the band structure. Photoluminescence spectroscopy (PL) is a strong technique to study these phenomena. The PL results record the emission spectra of electrons from high potentials jumping to low potentials ${ }^{25}$. A higher PL intensity might reflect high recombination of electron-hole pairs resulting in inadequate photocatalytic performance. However, the representation of PL results is often incorrect leading to incorrect conclusions. In 2013, Mooney and Kambhampati reviewed the proper Jacobian 
transformations for quantitative analysis of emission spectra ${ }^{26}$. To analyze PL results, firstly, the wavelength should be transformed into energy by eqn. (1). Secondly, this conversion of wavelength to energy should preserve the emission spectra area as eqn. (15) because the intensity vs. energy system $\left(\mathrm{I}_{\mathrm{E}}\right)$ is higher at lower energy and vice versa. In other words, the intensity vs. wavelength system $\left(\mathrm{I}_{\lambda}\right)$ should transform into $\mathrm{I}_{\mathrm{E}}$ as eqn. (16) - (17). Thirdly, IE could be calculated as eqn. (18) or eqn. (19) because the minus sign could be ignored without changing the properties of spectra. Finally, further evaluation of PL results could be conducted by fitting peaks with the Gaussian peak function. The fitting peaks may indicate

$$
\begin{gathered}
I_{E} d E=I_{\lambda} d \lambda \\
I_{E}=I_{\lambda} \frac{d \lambda}{d E} \\
I_{E}=I_{\lambda} \frac{d}{d E}\left(\frac{h v}{E}\right) \\
I_{E}=-I_{\lambda} \frac{h c}{E^{2}} \\
I_{E}=I_{\lambda} \frac{h c}{E^{2}}
\end{gathered}
$$

Where $\mathrm{I}_{\mathrm{E}}$ is signal per energy unit, $\mathrm{I}_{\lambda}$ is the signal per wavelength unit.

Figure 3 indicates the PL spectra of $\mathrm{TiO}_{2}, \mathrm{SnO}_{2}$, and $\mathrm{g}-\mathrm{C}_{3} \mathrm{~N}_{4}$; the spectra undergo Gaussian peak fitting to find component peaks. Figure 3 (a) indicates that $\mathrm{TiO}_{2}$ has 3 peaks at 1.82, 2.26, and $2.91 \mathrm{eV}$ accounting for $20.4 \%, 71.8 \%$, and $7.8 \%$, respectively. While the PL peak fitting of $\mathrm{SnO}_{2}$ (Figure $3(\mathrm{~b})$ ) has 3 peaks at $1.79 \mathrm{eV}, 2.03 \mathrm{eV}$, and $2.86 \mathrm{eV}$ accounting for $41.2 \%, 55.9 \%$, and $2.9 \%$, respectively. According to previous studies, these peaks of both $\mathrm{TiO}_{2}$ and $\mathrm{SnO}_{2}$ correspond to their instinct oxygen vacancies, which impact the charge carrier's separation resulting in a better photocatalytic performance ${ }^{14}$. For $g-\mathrm{C}_{3} \mathrm{~N}_{4}$, its PL peak fitting (Figure $3(\mathrm{c})$ ) shows 3 peaks at $2.48 \mathrm{eV}, 2.69 \mathrm{eV}$, and $2.84 \mathrm{eV}$ corresponded to the transitions of electrons from $\pi^{*}$ to $\pi$, from $\pi^{*}$ to lone pairs (LP), and from $\sigma$ to LP, respectively. The position and role of these transitions are illustrated in Figure 3 (d). 
Obviously, with the DRS, Mott-Schottky plots, and PL, the basic properties of the pure $\mathrm{TiO}_{2}, \mathrm{SnO}_{2}$, and $\mathrm{g}-\mathrm{C}_{3} \mathrm{~N}_{4}$ are being clarified. The next sections describe the changes of band alignment for the composites between them.
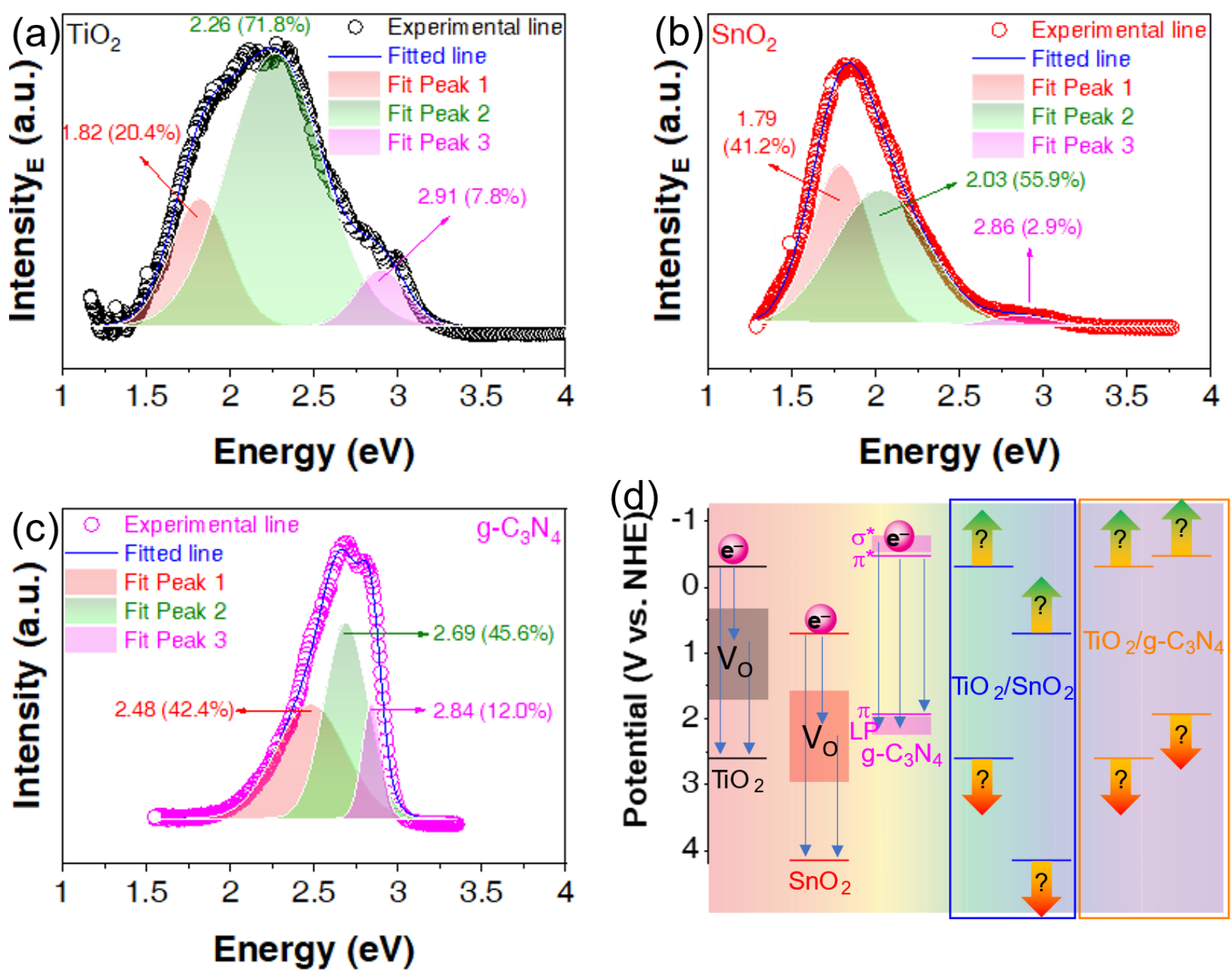

Figure 3. PL peak fitting of $\mathrm{TiO}_{2}$ (a), $\mathrm{SnO}_{2}$ (b), and $\mathrm{g}-\mathrm{C}_{3} \mathrm{~N}_{4}$ (c). Bandgap states of $\mathrm{TiO}_{2}$, $\mathrm{SnO}_{2}$, and $\mathrm{g}_{-} \mathrm{C}_{3} \mathrm{~N}_{4}$ (d). The combination of DRS spectra, Mott-Schottky, and PL cannot determine the changes in the band structure when materials are combined ${ }^{27}$.

\section{X-ray Photoelectron Spectroscopy}

For determining the composition of the photocatalysts, X-ray photoelectron spectroscopy (XPS) is well known as a powerful tool, but another application of XPS that should be considered is to determine the band offset of heterojunctions. Comparing to the mentioned approach of Mott-Schottky, evaluating band shifting with XPS is more accurate because XPS records the elements' core levels, which are more stable than the surface value. In other 
words, the VB offset could be accurately determined when the deviation of the core levels before and after contact is measured. The VB offset is calculated as eqn. (20) or (21), so the CB is calculated as eqn. (22) ${ }^{28}$. The exact position of band structure vs. NHE is useful in studying and applying for suitable applications, as mentioned above.

$$
\begin{gathered}
\Delta \mathrm{E}_{\mathrm{V}}=\left(\mathrm{E}_{\mathrm{VBM}}^{\mathrm{A}}+\mathrm{E}_{\mathrm{CL}}^{\mathrm{A} / \mathrm{AB}}-\mathrm{E}_{\mathrm{CL}}^{\mathrm{A}}\right)-\left(\mathrm{E}_{\mathrm{VBM}}^{\mathrm{B}}+\mathrm{E}_{\mathrm{CL}}^{\mathrm{B} / \mathrm{AB}}-\mathrm{E}_{\mathrm{CL}}^{\mathrm{B}}\right) \\
\Delta \mathrm{E}_{\mathrm{v}}=\left(\mathrm{E}_{\mathrm{CL}}^{\mathrm{A} / \mathrm{AB}}-\mathrm{E}_{\mathrm{CL}}^{\mathrm{B} / \mathrm{AB}}\right)-\left[\left(\mathrm{E}_{\mathrm{CL}}^{\mathrm{A}}-\mathrm{E}_{\mathrm{VBM}}^{\mathrm{A}}\right)-\left(\mathrm{E}_{\mathrm{CL}}^{\mathrm{B}}-\mathrm{E}_{\mathrm{VBM}}^{\mathrm{B}}\right)\right] \\
\Delta \mathrm{E}_{\mathrm{C}}=\mathrm{E}_{\mathrm{g}}^{\mathrm{A}}+\Delta \mathrm{E}_{\mathrm{V}}-\mathrm{E}_{\mathrm{g}}^{\mathrm{B}}
\end{gathered}
$$

When $\Delta \mathrm{E}_{\mathrm{V}}$ is the valence band offset $(\mathrm{eV}), \Delta \mathrm{E}_{\mathrm{C}}$ is the conduction band offset $(\mathrm{eV})$,

Figure 4 (a) and (b) show the XPS results and band alignment of $\mathrm{SnO}_{2} / \mathrm{TiO}_{2}$. The VB edges of pure $\mathrm{TiO}_{2}$ and $\mathrm{SnO}_{2}$ are 2.70 and 3.21, as shown in Figure 4 (c) and (d), respectively. When $\mathrm{SnO}_{2}$ and $\mathrm{TiO}_{2}$ are combined, there are shifts in core levels of Ti $2 \mathrm{p}$ and $\mathrm{Sn} 3 \mathrm{~d}$. If only DRS and Mott-Schottky are deployed, these shifts cannot be determined (Figure 4 (e)). These shifts in core levels could be used to determine the VB offset and CB offset (eqn. (20) - (22)) (Figure 4 (f)). Comparing before and after contact, the VB and CB offsets decrease when $\mathrm{SnO}_{2}$ and $\mathrm{TiO}_{2}$ in contact. These results could be due to the transfer of electrons from $\mathrm{TiO}_{2}$ (band structure goes down) to $\mathrm{SnO}_{2}$ (band structure goes up). The next section will explain this transfer. 

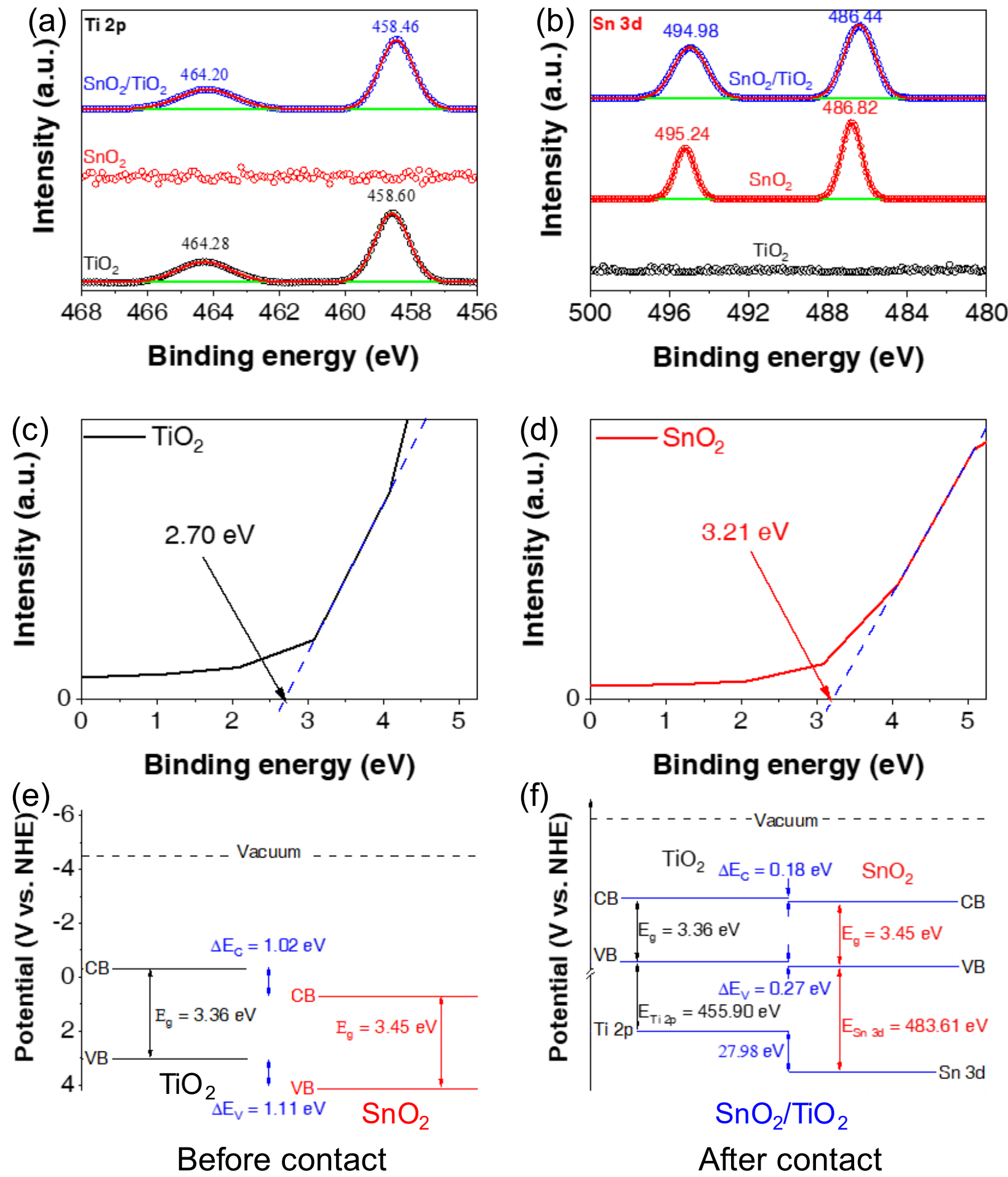

Figure 4. HR-XPS of Ti 2p (a) and $\mathrm{Sn} 3 \mathrm{~d}$ (b) components of $\mathrm{TiO}_{2}, \mathrm{SnO}_{2}$, and $\mathrm{SnO}_{2} / \mathrm{TiO}_{2}$. Valence band edge spectra of $\mathrm{TiO}_{2}$ (c) and $\mathrm{SnO}_{2}$ (d). Band alignment of materials before contact (e) and after contact (f) ${ }^{27}$. 


\section{Ultraviolet Photoelectron Spectroscopy}

Fermi energy level $\left(\mathrm{E}_{\mathrm{F}}\right)$ is an important part of the band structure; it helps determine the semiconductor type of photocatalysts and predict the transport of electrons in heterojunctions. Ultraviolet photoelectron spectroscopy (UPS) is the technique of recording $\mathrm{VB}$ and $\mathrm{E}_{\mathrm{F}}$ of photocatalysts. For UPS results, the $\mathrm{E}_{\mathrm{F}}$ is located at $0 \mathrm{eV}$, and the intersection of Ox and spectra tangent is relative VB position. Combining with the above techniques, the band structure of photocatalyst with $\mathrm{CB}, \mathrm{VB}, \mathrm{E}_{\mathrm{F}}$, trapping states vs. NHE can be revealed. In addition, the work function $(\varphi)$ can be directly determined by eqn. (23) ${ }^{29}$. The work function equals the difference between vacuum energy ( $\mathrm{E}_{\mathrm{vacuum}}$, at $4.5 \mathrm{~V}$ vs. $\mathrm{NHE}$ ) and $\mathrm{E}_{\mathrm{F}}$ (eqn. (24). Thus, UPS can be used to confirm consistency between the results. In addition, when photocatalysts are combined to fabricate heterojunction photocatalysts, there are the transports of electrons from photocatalysts with lower work function to photocatalysts with higher work function. This transport can induce internal electric fields to support or prevent the further transport of excited electrons of heterojunction photocatalysts under light irradiation. This is the explanation for the existence of type-II and Z-scheme photocatalysts.

$$
\begin{gathered}
\varphi=h v-\Delta E \\
\varphi=E_{\text {vacuum }}-E_{F}
\end{gathered}
$$

The UPS results of $\mathrm{TiO}_{2}, \mathrm{~g}-\mathrm{C}_{3} \mathrm{~N}_{4}$, and $\mathrm{TiO}_{2} / \mathrm{g}-\mathrm{C}_{3} \mathrm{~N}_{4}$ in Figure 5 (a) reveal the relative position of HOMO and VB to $\mathrm{E}_{\mathrm{F}}$ of them. Combining with DRS and Mott-Schottky results, the work function of these materials can be calculated by the difference between the Vacuum level and $E_{F}$. The electrons will transfer from the material having the lower work function $\left(\mathrm{g}-\mathrm{C}_{3} \mathrm{~N}_{4}\right)$ to the material having the higher work function $\left(\mathrm{TiO}_{2}\right)$ to balance the $\mathrm{E}_{\mathrm{F}}$. This is consistent with the work function of $\mathrm{TiO}_{2} / \mathrm{g}-\mathrm{C}_{3} \mathrm{~N}_{4}$ in Figure 5 (a). The band alignment of materials before and after contact is shown in Figure 5 (b). Due to the transfer of electrons from $\mathrm{g}_{-} \mathrm{C}_{3} \mathrm{~N}_{4}$ to $\mathrm{TiO}_{2}$, the band is bending, and an electric field is formed at the interface of $\mathrm{TiO}_{2} / \mathrm{g}-\mathrm{C}_{3} \mathrm{~N}_{4}$. This is a direct method for confirming the latest type of photocatalysts, known as Z-Scheme and S-Scheme. 


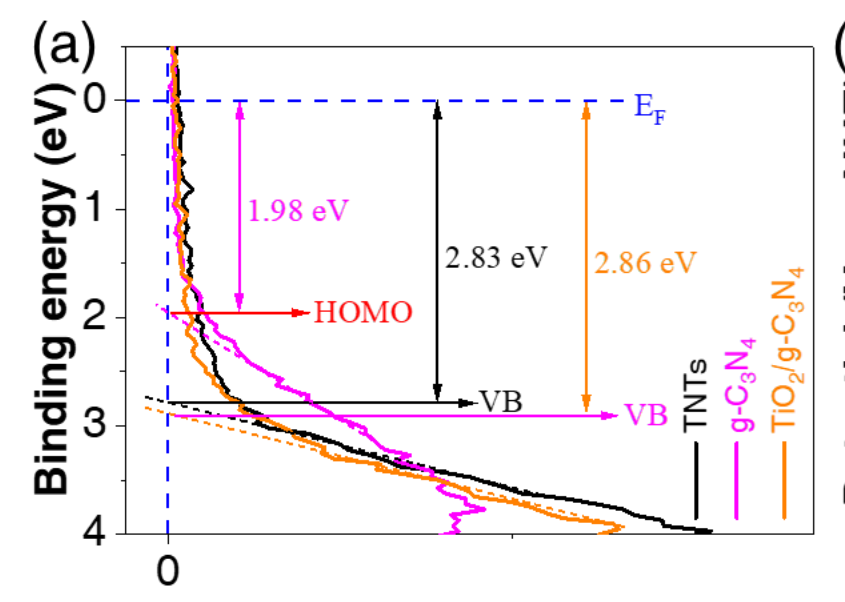

Intensity (a.u.)

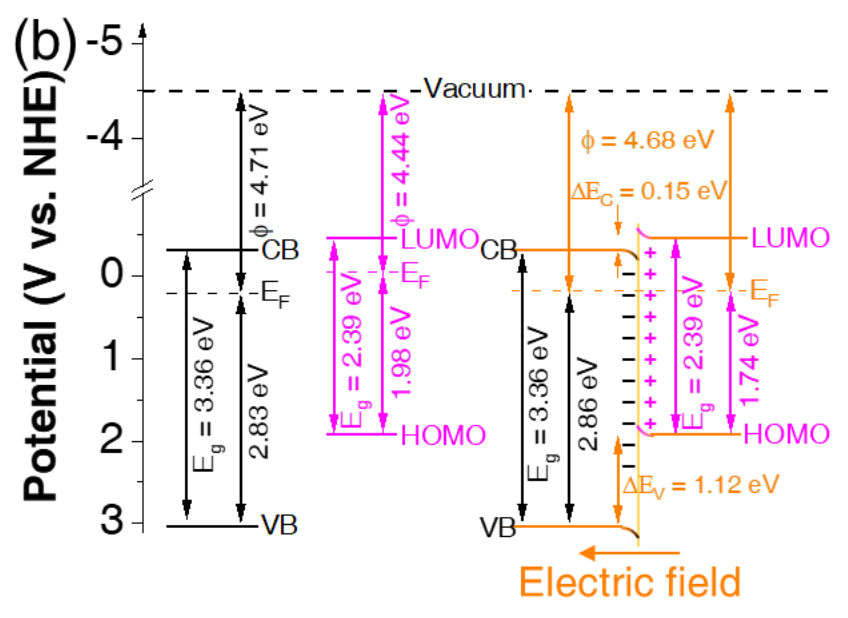

$\mathrm{TiO}_{2} \quad \mathrm{~g}-\mathrm{C}_{3} \mathrm{~N}_{4} \quad \mathrm{TiO}_{2} / \mathrm{g}-\mathrm{C}_{3} \mathrm{~N}_{4}$

Figure 5. UPS of $\mathrm{TiO}_{2}, \mathrm{~g}-\mathrm{C}_{3} \mathrm{~N}_{4}$, and $\mathrm{TiO}_{2} / \mathrm{g}-\mathrm{C}_{3} \mathrm{~N}_{4}$ (a). Band alignment of materials before contact and after contact (b) ${ }^{15}$.

\section{Conclusion and perspectives}

In this report, we have discussed the key optical and electrical characteristics in studying photocatalyst. The highlights and perspectives for future work are shown in the graphical abstract and described as follows:

(1) Bandgap energies determine the light source for activating photocatalysts. The DRS should be used to determine the bandgap energy of photocatalysts.

(2) Positions of conduction band minimum (CBM) and valence band maximum (VBM) determine the redox ability. The Mott-Schottky technique is used to determine the CB position. Combining with the bandgap from DRS, the VB position is also determined.

(3) Defects in the photocatalysts contribute to photocatalytic performance; they prolong the lifetime of electron-hole pairs via adding trapping states in the band structure. The PL results record the emission spectra of electrons from high potentials jumping to low potentials (trapping states). Combining with the VB and CB positions from Mott-Schottky, the trapping positions are determined.

(4) Comparing to the mentioned approach of Mott-Schottky, evaluating band shifting with XPS is more accurate because XPS records the elements' core levels, which are more stable 
than the surface value. XPS that should be considered is to determine the band offset of heterojunctions.

(5) Fermi energy level $\left(\mathrm{E}_{\mathrm{F}}\right)$ may determine the semiconductor type of photocatalysts and predict the transport of electrons in heterojunctions. UPS is the technique of recording the $\mathrm{VB}$ and $\mathrm{E}_{\mathrm{F}}$ of photocatalysts.
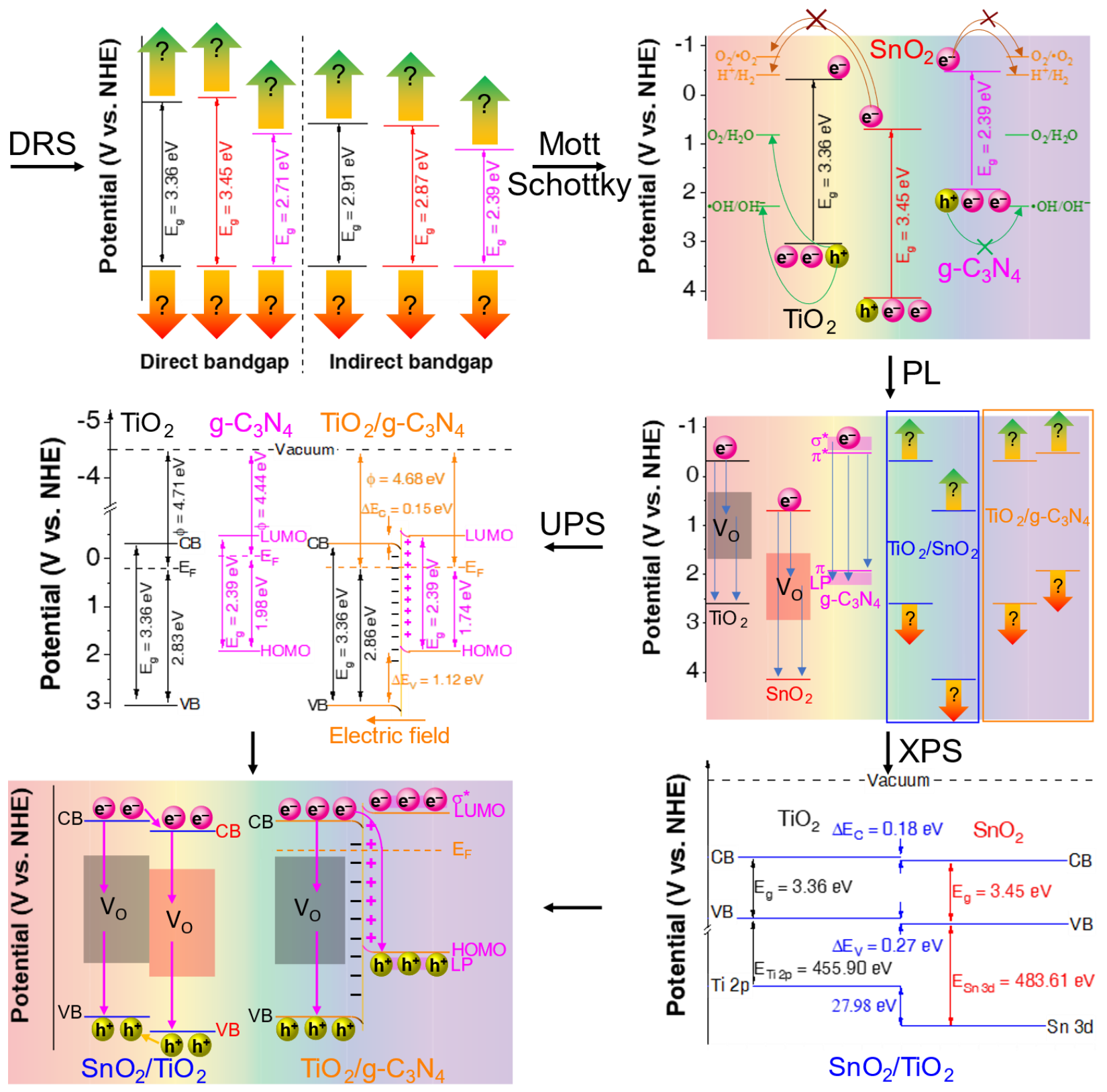

Graphical Abstract: Summary of approaches for study on photocatalysis 


\section{Acknowledgement}

The authors acknowledge the support of Prof. Sheng-Jie You, Prof. Ya-Fen Wang, Prof. Yong Soo Kim for XPS and UPS measurement.

\section{References}

1. UN (2019). Strategy for Sustainability Management in the UN System 2020-2030.

2. WHO (2016). An estimated 12.6 million deaths each year are attributable to unhealthy environments (who.int). https://www.who.int/news/item/15-03-2016-anestimated-12-6-million-deaths-each-year-are-attributable-to-unhealthyenvironments.

3. Zhang, X., Han, Y., Gao, P., and Li, Y. (2020). Effects of Grinding Media on Grinding Products and Flotation Performance of Chalcopyrite. Minerals Engineering 145. 10.1016/j.mineng.2019.106070.

4. Anantha, M.S., Olivera, S., Hu, C., Jayanna, B.K., Reddy, N., Venkatesh, K., Muralidhara, H.B., and Naidu, R. (2020). Comparison of The Photocatalytic, Adsorption and Electrochemical Methods for The Removal of Cationic Dyes from Aqueous Solutions. Environmental Technology \& Innovation 17. 10.1016/j.eti.2020.100612.

5. Byrne, C., Subramanian, G., and Pillai, S.C. (2018). Recent Advances in Photocatalysis for Environmental Applications. Journal of Environmental Chemical Engineering 6, 3531-3555. 10.1016/j.jece.2017.07.080.

6. Jiang, L., Wang, Y., and Feng, C. (2012). Application of Photocatalytic Technology in Environmental Safety. Procedia Engineering 45, 993-997. 10.1016/j.proeng.2012.08.271.

7. Liu, Y., Wang, H., Yuan, X., Wu, Y., Wang, H., Tan, Y.Z., and Chew, J.W. (2021). Roles of Sulfur-Edge Sites, Metal-Edge Sites, Terrace Sites, and Defects in Metal Sulfides for Photocatalysis. Chem Catalysis. 10.1016/j.checat.2021.01.002.

8. Tauc, J. (1968). Optical Properties and Electronic Structure of Amorphous Ge and Si. Materials Research Bulletin 3, 37-46. 10.1016/0025-5408(68)90023-8.

9. Johannes, A.Z., Pingak, R.K., and Bukit, M. (2020). Tauc Plot Software: Calculating Energy Gap Values of Organic Materials Based on Ultraviolet-Visible Absorbance Spectrum. IOP Conference Series: Materials Science and Engineering 823. 10.1088/1757-899x/823/1/012030.

10. Makula, P., Pacia, M., and Macyk, W. (2018). How To Correctly Determine the Band Gap Energy of Modified Semiconductor Photocatalysts Based on UV-Vis Spectra. The Journal of Physical Chemistry Letters 9, 6814-6817. 10.1021/acs.jpclett.8b02892.

11. Iani, I.M., Teodoro, V., Marana, N.L., Coleto, U., Sambrano, J.R., Simões, A.Z., Teodoro, M.D., Longo, E., Perazolli, L.A., A. C. Amoresi, R., and Aparecida Zaghete, M. (2021). Cation-Exchange Mediated Synthesis of Hydrogen and Sodium Titanates Heterojunction: Theoretical and Experimental Insights Toward 
Photocatalyic Mechanism. Applied Surface Science 538. 10.1016/j.apsusc.2020.148137.

12. Xu, Q., Zhang, L., Cheng, B., Fan, J., and Yu, J. (2020). S-Scheme Heterojunction Photocatalyst. Chem 6, 1543-1559. 10.1016/j.chempr.2020.06.010.

13. Sharma, S., Dutta, V., Raizada, P., Hosseini-Bandegharaei, A., Thakur, V.K., Kalia, S., Nguyen, V.-H., and Singh, P. (2021). Recent Advances in Silver Bromide-Based Z-scheme Photocatalytic Systems for Environmental and Energy Applications: A review. Journal of Environmental Chemical Engineering 9. 10.1016/j.jece.2021.105157.

14. Van Viet, P., Huy, T.H., Sang, N.X., Thi, C.M., and Van Hieu, L. (2017). One-Step Hydrothermal Synthesis and Characterisation of $\mathrm{SnO}_{2}$ Nanoparticle-Loaded $\mathrm{TiO}_{2}$ Nanotubes with High Photocatalytic Performance under Sunlight. Journal of Materials Science 53, 3364-3374. 10.1007/s10853-017-1762-6.

15. Duong, D.P.T., Doan Van, T., Bui Dai, P., Nguyen Tran, T.N., Nguyen, T.N.U., Cao Minh, T., Nguyen, T.K., Kim, Y.-S., and Pham Van, V. (2019). Excellent Visible Light-Driven Photocatalytic Performance and Band Alignment of g- $\mathrm{C}_{3} \mathrm{~N}_{4} / \mathrm{TiO}_{2}$ Nanotube Heterostructures. Materials Research Express 6. 10.1088/20531591/ab2021.

16. Gelderman, K., Lee, L., and Donne, S.W. (2007). Flat-Band Potential of A Semiconductor: Using the Mott-Schottky Equation. Journal of Chemical Education 84. 10.1021/ed084p685.

17. Li, X., Yu, J., and Jaroniec, M. (2016). Hierarchical Photocatalysts. Chemical Society Reviews 45, 2603-2636. 10.1039/c5cs00838g.

18. Meites, L. (1963). Handbook of Analytical Chemistry. Soil Science 96, 358.

19. Zoski, C.G. (2006). Handbook of Electrochemistry (Elsevier).

20. Bard, A.J., and Faulkner, L.R. (2001). Fundamentals and Applications. Electrochemical Methods 2, 580-632.

21. Friis, E.P., Andersen, J.E.T., Madsen, L.L., Bonander, N., Møller, P., and Ulstrup, J. (1998). Dynamics of Pseudomonas Aeruginosa Azurin and Its Cys3Ser Mutant at Single-Crystal Gold Surfaces Investigated by Cyclic Voltammetry and Atomic Force Microscopy. Electrochimica Acta 43, 1114-1122. 10.1016/s00134686(98)99006-5.

22. Sawyer, D.T., Sobkowiak, A., and Roberts, J.L. (1995). Electrochemistry for Chemists (Wiley).

23. Fenelon, E., Bui, D.P., Tran, H.H., You, S.J., Wang, Y.F., Cao, T.M., and Van Pham, V. (2020). Straightforward Synthesis of $\mathrm{SnO}_{2} / \mathrm{Bi}_{2} \mathrm{~S}_{3} / \mathrm{BiOCl}_{-} \mathrm{Bi}_{24} \mathrm{O}_{31} \mathrm{Cl}_{10}$ Composites for Drastically Enhancing Rhodamine B Photocatalytic Degradation under Visible Light. ACS Omega 5, 20438-20449. 10.1021/acsomega.0c02461.

24. Bui, D.P., Pham, H., Cao, T., and Pham, V. (2020). Preparation of Conjugated Polyvinyl Chloride/TiO 2 Nanotubes for Rhodamine B Photocatalytic Degradation under Visible Light. Journal of Chemical Technology \& Biotechnology. 10.1002/jctb.6466.

25. Jorio, A. (2008). In Carbon Nanotubes; Jorio, A., Dresselhaus, G., Dresselhaus, MS, Eds. Topics in Applied Physics. 
26. Mooney, J., and Kambhampati, P. (2013). Get the Basics Right: Jacobian Conversion of Wavelength and Energy Scales for Quantitative Analysis of Emission Spectra. The Journal of Physical Chemistry Letters 4, 3316-3318. 10.1021/jz401508t.

27. Huy, T.H., Bui, D.P., Kang, F., Wang, Y.F., Liu, S.H., Thi, C.M., You, S.J., Chang, G.M., and Pham, V.V. (2019). $\mathrm{SnO}_{2} / \mathrm{TiO}_{2}$ Nanotube Heterojunction: The First Investigation of NO Degradation by Visible Light-Driven Photocatalysis. Chemosphere 215, 323-332. 10.1016/j.chemosphere.2018.10.033.

28. Chen, S., Pan, X., Xu, C., Huang, J., and Ye, Z. (2016). X-ray Photoelectron Spectroscopy Study of Energy-Band Alignments of $\mathrm{ZnO}$ on Buffer Layer $\mathrm{Lu}_{2} \mathrm{O}_{3}$. Physics Letters A 380, 970-972. 10.1016/j.physleta.2015.12.038.

29. Maheu, C., Cardenas, L., Puzenat, E., Afanasiev, P., and Geantet, C. (2018). UPS and UV Spectroscopies Combined to Position the Energy Levels of $\mathrm{TiO}_{2}$ Anatase and Rutile Nanopowders. Physical Chemistry Chemical Physics 20, 25629-25637. $10.1039 / \mathrm{c} 8 \mathrm{cp} 04614 \mathrm{j}$. 